anthracite, ought not to rejoice in a pure and transparent atmosphere.

Similarly, the South Wales coal and iron districts would be centres of fog-clouds and mist, like Birmingham and Newcastle. But they are as free from fog as the purely pastoral valleys of Wales.

Next, as to persistency. Early in the morning of January $3 \mathrm{I}$ last, in some districts of London the fog extended considerably above the tops of the houses, in others only about 1o or 20 feet from the ground in any intensity. Where the fog extended high the smuke mixed with it and produced a yellow fog, but where it remained low the smoke escaped into the upper air and drifted away, leaving a white fog below, so pure as to be a very.unusual phenomenon at $\mathrm{IO}$ a.m. in a London street. Now it was remarkable, that wherever the white fog prevailed in the morning, the sun soon obtained the $\mathrm{m}$ istery and dispelled it more or less, but in the smoke-obscured districts a dark yellow fog continued throughout the day.

White fogs nay doubtless be exceedingly dense. But will not an admixture of smoke increase its density?

A humid atmosphere is not necessary for the production of mist and haze. The frequent long-continued prevalence of blue haze over the whole country, not excepting the east coasts, in the driest east winds of spring, wonld be a subject deserving investi gation. They sometimes extend to a height much above the tops of our highest mountains. Experiments such as tho:e of Mr. Aitken will, we may hope, ultimately solve this problem of meteorology.

R. RUSSELL

\section{Low Temperature}

THE reading of the thermometer here last night, January 15,16 , was the lowest ever recorded at this o'servatory in the course of thirty three years. The reading was $4^{\circ} \cdot 6 \mathrm{~F}$., the previous minimum having occurred on December 24,1860 , when the mercury stood at $6^{\circ} \cdot 7 \mathrm{~F}$.

Stonyhurst Observatory, January $\mathrm{i} 6$

\section{A "Natural" Experiment in Polarised Light}

BREAK off a plate of ice and hold it between the sky and a pool of water. Its reflected image will show the beautiful colours due to polarised light. The incident rays should come from a part of the sivy about $90^{\circ}$ from the sun, and reflection should take place at the polarising angle for water, and the plate will probahly require adju ting to bring out the maximum effect. Water, va orous, solid, and liquid, thus furnishes us with pol iriser, crystal, and analycer I (io not remember to have read any account of this very simple experiment, for which Nature provides all the materials.

9, Beech Grove, Harrogate, January 10 CHAS. ' 1 . IVHITMELL

\section{STATICS AND DYNAMICS OF SKATING}

MANY years ago, when skating was but in its infancy, skates were made of bone, and if they could be made to stay on the feet they were considered to answer their purpose sufficiently well.

More recently iron rumners with wooden beds came into use, and accuracy of adjustment on the foot, horizontally and longitudinally, was made easier by means of leather straps and a screw passing into the heel of the boot; and these adjustinents, made haphazard, were quite sufficient for the skating of those days, namely forward skating.

Within the last twenty years however skating has made enormous strides, back skating becoming an essential qualification of a finished skater; and hence not only more perfect forms of state are demanded from the maker, but also the adjustment of them on the boot becomes an important part of his duty.

There are three points to be attended to in the adjustment of the s'rate, besides the obvious one of placing the skate medially on the foot.

1. Height of foot off the ise where the greatest breadth of the sole of boot occurs.

2. Height of foot off ice at the heel.

3. Position of the skate longitudinally or lengthwise on the foot.
First. The height of the foot from the ice should be such as will enable the skater to lean over sufficiently when on a curve, and such that he may be able to get a powerful enough stroke. If he is too low the edge of the boot will come in contact with the ice in leaning overt and also in taking a stroke : a fall ensuing in the firs, case, and a disagreeable and dangerous overstrain in the second. To avoid these the sole of the boot should subtend an angle at the botto:n of the runner of about 96 deg. i.e. for a sole $3 \frac{1}{2}$ inches broad the edge of the runner should be $1 \frac{1}{2}$ inch from the sole, instead of varying from $\mathrm{I}_{8}^{7}$ to $1 \frac{1}{8}$ inch, which are the heights of skates commonly met with.

This angle of $96 \mathrm{deg}$. will be found to clear the ice in both striking and leaning over for most skaters, and any greater height than is given by this angle should not be used, as it is not necessary, and only throws an additional strain on the ankle.

Second. The height at the sole having been fixed, the next point is what should be the height at the heel? In fact is the foot to be parallel to the skate, or is it to rest on an incline?

Dove was the first person, in his "Skater's Monitor," published in Edinburgh in 1846 , to write on the position of the skate on the foot, summing up his remarks by saying, "Level woods then are for shoes whose heels
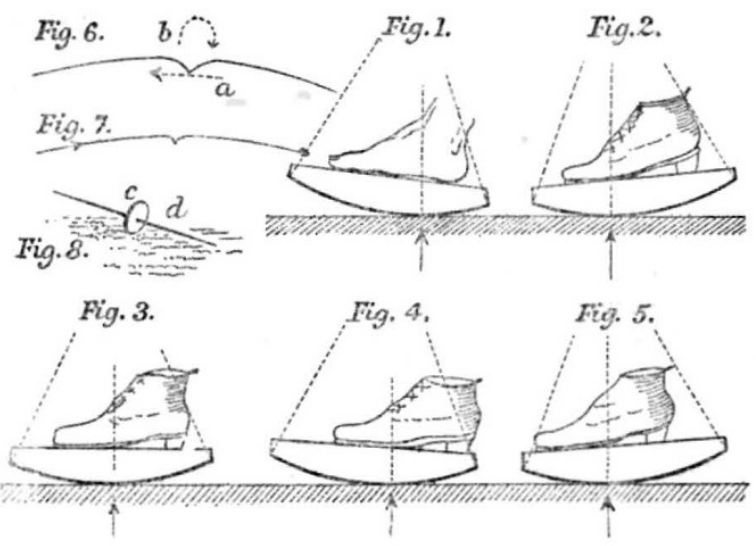

and soles are equally prominent, but high heels must be sunk into the skate-woods." This was quite correct at that time, when back skating was little practised, and when the skate which was then worn was made very flat, in fact almost straight at and near the heel. Now, by universal consent for figure-skating, the iron is made a segment of a single circle from toe to heel, $7 \frac{1}{2}$ feet being the radius. Yet, notwithstanding these changes, Vandervell and Witham, as lately as January, I880, in their "Figure Skating," recommend the very same parallelism of the foot to the skate instead of parallelism of the top of the blade to the ice, as it should be for modern skating, as I shall subsequently show.

In Fig. I is shown the result of adopting Dove's or Vandervell and Witham's position, i.e. no heel. It might be thought that a person standing on a curve would balance comfortably at the middle of the curve, but this cannot be, for a person standing naturally on a level surface does not distribute the weight of his body equally over the length of his foot, but by far the gre?ter part comes on the heel, and therefore the centre of pressure of his boty is nearer the heel than the toe, and consequently if he is standing on a curve the curve must roll up in front and down behind till the upward pressure of the ice just passes through the centre of pressure of his body. The point of contact of the skate on the ice will therefore not only be much behind the centre of the skate, but will be a little behind the centre of pressure of his body when standing on a level surface, as he now 